\title{
Treatment with the Noradrenergic Alpha-2 Agonist Clonidine, But Not Diazepam, Improves Spatial Working Memory in Normal Young Rhesus Monkeys
}

Jenna S. Franowicz, M.Phil., and Amy F.T. Arnsten, Ph.D.

Noradrenergic $\alpha$-2 agonists such as clonidine and guanfacine improve working memory performance in aged monkeys. Guanfacine also improves cognition in young monkeys, but there are conflicting reports of the effects of clonidine in young adult human and nonhuman primates. In the present study, high doses of clonidine $(0.02-0.1 \mathrm{mg} /$ $\mathrm{kg}$ ) significantly improved performance of the delayed response task, a test of spatial working memory, in young adult monkeys. Lower doses (0.0001-0.01 mg/kg), similar to those used in human studies (0.001-0.003 mg/kg), had no effect on task performance. In contrast, monkeys experimentally depleted of catecholamines by chronic reserpine treatment have been improved by both dose ranges. These results provide further support for the hypothesis that $\alpha-2$ agonists improve cognition via actions at post-synaptic $\alpha$-2 receptors, and suggest that conflicting results with clonidine in previous studies of prefrontal cortical function may result from insufficient dosage. [Neuropsychopharmacology 21:611-621, 1999] (C) 1999 American College of Neuropsychopharmacology. Published by Elsevier Science Inc.
KEY WORDS: Prefrontal cortex; $\alpha-2$ agonists;

Norepinephrine; Working memory

Alpha-2 noradrenergic agonists are known for their effects on a wide range of central and peripheral functions, such as analgesia, opiate withdrawal, cardiovascular control, sedation, attention, anxiety, feeding, and temperature and hormonal regulation. They have many clinical uses, including as a preanaesthetic, to control blood pressure, and to treat insomnia, Tourette's syndrome, and attention deficit hyperactivity disorder. This broad range of effects is consistent with the broad

From the Section of Neurobiology, Yale University School of Medicine, New Haven, CT.

Address correspondence to: Dr. Jenna S. Franowicz, Section of Neurobiology, Yale University School of Medicine, 333 Cedar St., New Haven, CT 06520-8001.

Received December 4, 1998; revised April 30, 1999; accepted May 17,1999 . projections of the noradrenergic system along the length of the neuroaxis. One aspect of $\alpha-2$ receptor function receiving increasing examination is its role in cognitive processing.

Clonidine and other $\alpha-2$ agonists have previously been shown to improve spatial working memory in animals that have depleted levels of NE. This effect is seen when NE is depleted globally or when limited to the prefrontal cortex (PFC). In monkeys, a 6-OHDA lesion of the PFC, causing significant depletion of both dopamine and NE, produced as profound an impairment on the delayed alternation task as removal of the cortex itself (Brozoski et al. 1979). Clonidine significantly improved performance in these 6-OHDA treated monkeys, and was most potent in those animals with the greatest NE loss in the PFC (Arnsten and GoldmanRakic 1985). Aged monkeys, with naturally occurring catecholamine depletion, are also improved by $\alpha-2$ agonist treatment (Arnsten and Goldman-Rakic 1985; Arn- 
sten et al. 1988; Jackson and Buccafusco 1991; Rama et al. 1996) as were animals with NE depletion produced by reserpine (Cai et al. 1993) or MPTP (Schneider and Kovelowski 1990). Aged rats are also improved by $\alpha-2$ agonists (Tanila et al. 1996). In humans, clonidine has been used clinically to treat disorders thought to involve prefrontal cortical dysfunction, such as mania (Hardy et al. 1986; Bakchine et al. 1989), ADHD (Hunt et al. 1985), and Tourette's syndrome (Cohen et al. 1980) and has been shown to improve PFC tasks in patients with Korsakoff's syndrome (Mair and McEntee 1986) and schizophrenia (Fields et al. 1988).

Although improvements in human patients and catecholamine-depleted animals have been described, it is less clear whether $\alpha-2$ agonists can produce cognitive enhancement in normal subjects. In normal young monkeys, Jackson and Buccafusco (1991) found a very small but significant improvement (about $3 \%$ ) in working memory following low doses of clonidine, but animals did not perform on this task following higher doses. In human volunteers, clonidine has been found to both increase or decrease task performance, depending on the task and the dose used. Most typically, low doses of clonidine, in the range of $0.001-0.003 \mathrm{mg} / \mathrm{kg}$ have been found to impair human subjects on tasks involving sustained attention (Clark et al. 1989; Coull et al. 1995b) and paired associate learning (Frith et al. 1985). Imaging studies have found these impairments to be accompanied by decreases in rCBF in the thalamus, mostly during low-arousal states (Coull et al. 1997).

Some studies have found that these same low doses can improve performance on spatial working memory and paired associate learning tasks (Coull et al. 1995a, b). However, another recent study found that clonidine did not improve working memory in humans (Jakala et al. in press). It is likely that lower doses of clonidine used in these studies primarily engage pre-synaptic $\alpha-2$ receptors, decreasing LC firing, and decreasing NE release. Slightly higher doses may begin to engage postsynaptic receptors, and the opposing actions at preversus post-synaptic receptors may contribute to the conflicting results often observed in human cognitive studies. Given these inconsistent findings in humans, the current experiment was undertaken to examine a broad range of clonidine doses. It is important to examine in young animals the effects of clonidine as well as guanfacine, even though evidence suggests guanfacine is the more interesting drug to pursue. First, a comparison of the effects of the two drugs could further clarify receptor mechanisms. Second, clonidine, as the prototypical alpha-2 agonist, is much more widely used than guanfacine both clinically and in basic research and it is thus useful to study its effects separately.

The effects of the anxiolytic diazepam have also been examined on tests of attention and memory in human subjects. This benzodiazepine and clonidine act on dif- ferent neurotransmitter systems, but can produce some overlapping behavioral and physiological effects. Diazepam has been widely used as an anxiolytic medication and clonidine has also been found to decrease anxiety (Hoehn-Saric et al. 1981). Like clonidine, diazepam can decrease firing of the locus coeruleus (Grant et al. 1980), attenuate both basal and stress induced NE release in the $\mathrm{mPFC}$ (Rossetti et al. 1990), attenuate dopamine release in the nucleus accumbens (Murai et al. 1998), and attenuate sensory evoked acetylcholine release in the medial PFC in rodents (Acquas et al. 1998). In order to address the possibility that clonidine may be effecting task performance indirectly by altering measures also effected by diazepam, the current study also characterized delayed response performance in young monkeys following diazepam treatment (1.0, 2.0, and $3.0 \mathrm{mg} / \mathrm{kg}$ ). These doses are known to be anxiolytic and sedative in humans and in monkeys (Wayner et al. 1989; Dawson et al. 1995).

\section{METHODS}

\section{Subjects}

The animals used in this study were 6 young adult female rhesus monkeys (Macaca mulatta) ranging in age from 4 years (post-pubescent) to 15 years (late middle aged). The monkeys were individually housed and maintained on a diet of Purina monkey chow supplemented with fruit. Care of the animals followed the guidelines in "Guide For the Care and Use of Laboratory Animals" and was approved by the Yale Animal Care and Use Committee. Animals were always tested at the same time of day immediately prior to feeding. Highly palatable food rewards (e.g., peanuts, raisins or chocolate chips) were utilized during testing to minimize the need for dietary regulation. Each animal's preferred reward was determined early in their cognitive testing history and was typically the only reward used for this animal for the duration of the study. Occasionally an animal showed signs of tiring of a specific food reward; in this case the reward was changed and drug was not administered until the animal was again performing in a stable manner.

\section{Delayed Response Testing}

Cognitive testing occurred in a Wisconsin General Testing Apparatus (WGTA) situated in a sound-attenuating room. Background masking noise $(60 \mathrm{~dB}$, wideband) was also used to minimize auditory distractions. The monkeys had been trained on the 2-well delayed response task as described previously (Arnsten et al. 1988). During delayed response, the animal watches as the experimenter baits one of two foodwells with a food 
reward. Care is taken by the experimenter to ensure that the animal attends the baiting procedure. The foodwells are then covered with identical cardboard plaques, and an opaque screen is lowered between the animal and the tester for a specified delay. At the end of the delay, the screen is raised and the animal is allowed to choose. Reward is quasi-randomly distributed between the left and right wells over the 30 trials that make up a daily test session. Five different delay lengths (referred to as delays A through E) were also quasi-randomly distributed over these 30 trials. The shortest of these delays was less than 1 second (the " 0 " sec A delay). The remaining delays were in the range which for each individual monkey yielded baseline performance of about $70 \%$ across all delays (i.e., 18-22 trials correct of the possible 30 trials). For example the delays for one animal might be $\mathrm{A}=0, \mathrm{~B}=5, \mathrm{C}=10, \mathrm{D}=$ 15 , and $\mathrm{E}=20$ seconds. The $\mathrm{B}$ delay for the five animals ranged between 5 and 30 seconds; therefore the $\mathrm{E}$ delay ranged from 20 and 120 seconds. The animals were tested twice a week with 3-4 days separating each test session (e.g., Monday and Thursday).

\section{Sedation Assessment}

Sedation and agitation were rated using a 9 point scale where $-\mathrm{IV}=$ too agitated to test, $-\mathrm{III}=$ agitation which interferes with testing, - II $=$ slight agitation which does not interfere with testing, $-\mathrm{I}=$ more alert than usual, $0=$ normal level of arousal, $\mathrm{I}=$ quieter than usual, II = sedated (drooping eyelids, slowed movements), III = intermittent sleeping, and IV = too sedated to test. Aggression was rated using a similar scale where - III = dramatically more aggressive, - II = moderately more aggressive, $-\mathrm{I}=$ mildly more aggressive, 0 = normal, $\mathrm{I}=$ mildly less aggressive, $\mathrm{II}=$ moderately less aggressive, and III = dramatically less aggressive.

\section{Drug Administration}

Drug solutions were made up fresh each day under sterile conditions. A washout period of at least 10 days occurred between all drug treatments. Each drug treatment was only administered when a monkey was exhibiting stable performance on the delayed response task (at least two consecutive testing days of performance between 18 and 22 correct). The order of dose administration was determined quasi-randomly, and the experimenter testing the animal was unaware of the treatment condition. Each animal was administered saline at a point when drug would have been administered at least three times during the course of the study. Clonidine was diluted in sterile saline and injected intramuscularly (IM) one hour before each testing ses- sion. The clonidine doses tested were $0.0001,0.001,0.01$, $0.02,0.05$, and $0.1 \mathrm{mg} / \mathrm{kg}$. The dose which best improved task performance for each animal was repeated alone and in combination with the $\alpha-2$ adrenergic antagonist idazoxan $(0.1 \mathrm{mg} / \mathrm{kg}$, i.m. $)$ one hour prior to testing. Diazepam $(1.0,2.0$, or $3.0 \mathrm{mg} / \mathrm{kg})$ was injected i.m. two hours before the testing session. These doses were chosen to be greater than anxiolytic doses in humans (2-20mg or about $0.1-0.3 \mathrm{mg} / \mathrm{kg}$ ), but not severely sedating in monkeys (Schulze et al. 1989; Wayner et al. 1989). Clonidine was generously donated by Boehringer Ingelheim, Ridgefield, CT. Idazoxan was purchased from RBI, Natick, MA, and diazepam was purchased from Steris Laboratories, Inc, Phoenix, AZ.

\section{Data Analysis}

As the animals served as their own controls, statistical analyses employed repeated measures designs: paired $t$-test (also called dependent $t$-test or $t$-dep), and one- or two-way analyses of variance with repeated measures (ANOVA-R) with planned comparisons (1-ANOVA-R on effect of drug dose; 2-ANOVA-R on effect of drug dose and effect of delay interval; with test of effects). The effect of dose of clonidine on number correct was tested using a 1-ANOVA-R for saline and the six clonidine doses. A 2-way repeated measures ANOVA compared performance over the five delay lengths for saline and the six clonidine doses. A paired $t$ test was used for comparison of saline vs. clonidine + idazoxan. Nonparametric analysis (Wilcoxon) was used for analysis of the sedation rating data.

\section{RESULTS}

\section{Effect of Clonidine Treatment on Delayed Response Performance}

Clonidine treatment significantly altered delayed response performance [1-ANOVA-R: $\mathrm{F}(6,30)=2.69, p=$ .03]. Figure 1 shows the mean number of trials correct on the delayed response task (top graph) and the mean sedation ratings (bottom graph) for all six animals. Post-hoc tests revealed that both $0.02 \mathrm{mg} / \mathrm{kg}(\mathrm{F}(1,5)=$ $7.013, p<.05)$ and $0.1 \mathrm{mg} / \mathrm{kg}(\mathrm{F}(1,5)=8.741, p<.05)$ clonidine significantly improved task performance when compared to saline. There was a trend towards improvement following $0.05 \mathrm{mg} / \mathrm{kg}$ clonidine $(\mathrm{F}(1,5)=$ $5.058, p=.07)$. At this dose there was significant variability between monkeys in both cognitive performance and sedation which may account for the trend not reaching significance. Figure 2 shows individual doseresponse curves for each of the six animals following treatment with each dose of clonidine. To test the reliability of the effect, in four of the six animals the most 
efficacious dose of clonidine (see Table 1) was repeated and significantly improved performance (saline (20.16 \pm trials correct) vs. repetition of clonidine $(23.75 \pm .73$ trials correct) $t$-test: $p<.02$ ).

Delay analysis revealed a significant effect of clonidine $(\mathrm{F}(6,30)=3.10, p<.02)$ and a significant effect of delay $(F(4,20)=13.623, p<.0001)$ but no interaction. The effects of the most efficacious dose of clonidine (see Table 1) and saline on performance at the five different delay lengths are shown in Figure 3. As expected, with saline treatment, performance worsened with increasing delay. However, it is important to note that the animals made errors at the " 0 " second delays as well. These errors likely arose from the distracting effects of the screen rapidly lowering and rising. As can be seen in Figure 3, clonidine treatment improved task performance at all delays.

The effect of clonidine on delayed response performance
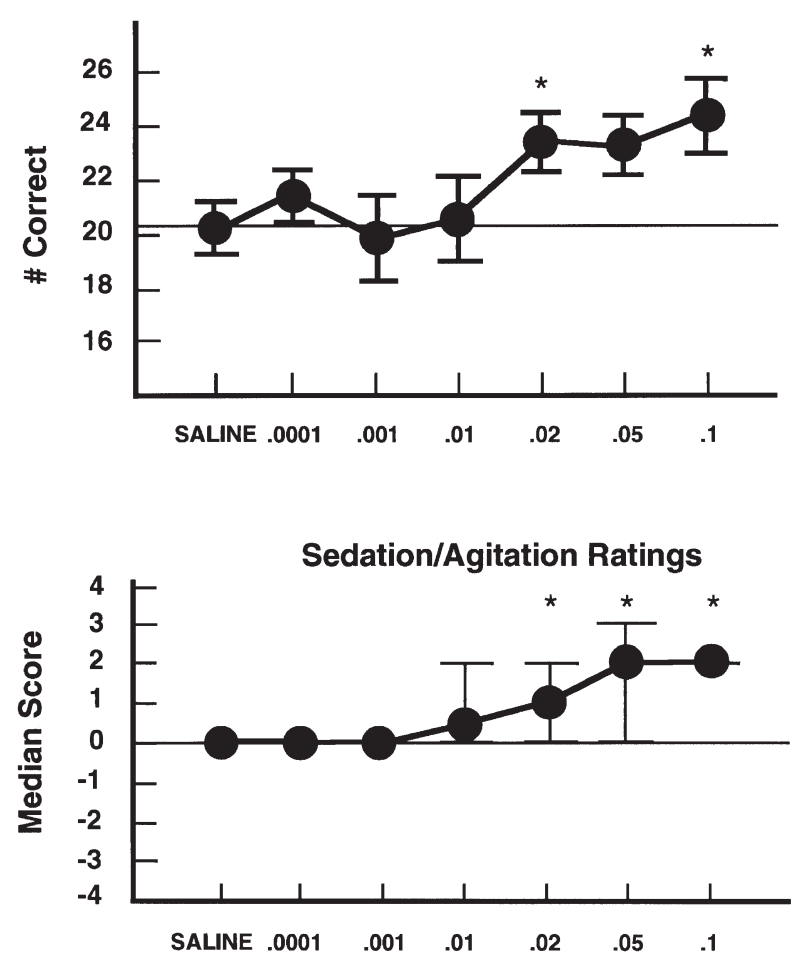

Dose Clonidine ( $\mathrm{mg} / \mathrm{kg})$

Figure 1. The average effect of clonidine on delayed response performance and sedation ratings $(n=6)$. A. Shown are mean \pm SEM trials correct out of a possible 30 trials following saline or clonidine $(0.0001-0.1 \mathrm{mg} / \mathrm{kg})$ treatment. B. Shown are median sedation/agitation scores \pm range following saline or clonidine $(0.0001-0.1 \mathrm{mg} / \mathrm{kg})$ treatment. ${ }^{*}=$ significant difference from saline.

\section{Sedation}

Figure 1 shows the median sedation rating \pm range for all six animals following clonidine treatment. The three highest doses of clonidine tested produced significant experimenter-rated sedation. The median score following $0.02 \mathrm{mg} / \mathrm{kg}$ was I, quieter than usual (Wilcoxon: $p<.045)$; the median score following $0.05 \mathrm{mg} / \mathrm{kg}$ was II, sedated, with scores ranging from 0 (normal) to III (intermittent sleeping) (Wilcoxon: $p<.05$ ) whereas all monkeys were scored as II, sedated, following $0.1 \mathrm{mg} /$ $\mathrm{kg}$ (Wilcoxon: $p=.02$ ). The median score following 0.01 $\mathrm{mg} / \mathrm{kg}$ was 0.25 (Wilcoxon $p>.1$ ) and following all lower doses was 0 (normal). The most efficacious dose of clonidine (see Table1) also significantly increased sedation ratings (median score $=1.875$, range $0-$ II, Wilcoxon $p=.068)$.

\section{Reversal by Idazoxan}

For each animal, the most efficacious dose of clonidine (see Table 1) was challenged with the $\alpha-2$ antagonist, idazoxan $(0.1 \mathrm{mg} / \mathrm{kg})$. As shown in Figure 4, performance following the combined treatment $(20.75 \pm 1.13$ trials correct) was not significantly different from performance following saline treatment ( $t$-test: $p=.63$ ), and was significantly different from performance following clonidine treatment alone ( $t$-test: $p=.03)$. Idazoxan also reversed the sedation produced by clonidine (Wilcoxon clon vs. clon + ida: $p=.03$ ), returning all sedation rating scores to 0 (normal).

\section{Effect of Diazepam Treatment on Delayed Response Performance}

The mean \pm SEM trials correct following saline, or diazepam $(1.0,2.0$, or $3.0 \mathrm{mg} / \mathrm{kg}$ ) are shown in Figure 5 . No dose of diazepam tested effected delayed response performance. At the $2.0 \mathrm{mg} / \mathrm{kg}$ dose, the data from only three of the four animals are included in the mean, as one animal, who was described as slightly ataxic and agitated, refused to finish testing (10/16 correct). At the $3.0 \mathrm{mg} / \mathrm{kg}$ dose, two of the four animals were described as quieter and ataxic. At the 3.0 $\mathrm{mg} / \mathrm{kg}$ dose, the median sedation score was 0.5 (between normal and quiet; Wilcoxon sal vs. dzp: $p=$ .576). Experimenter-rated sedation following diazepam was not significantly different from saline, ranging from II (sedated) to - II (slightly agitated). No measurements of reaction time were taken, and it is likely that the relatively crude sedation rating scale used here may be less sensitive than automated procedures in detecting subtle changes in sedation. Additionally, diazepam can disinhibit behavior, which may lead to sedation scores of -II. 
Monkey \#93-38 - age 6

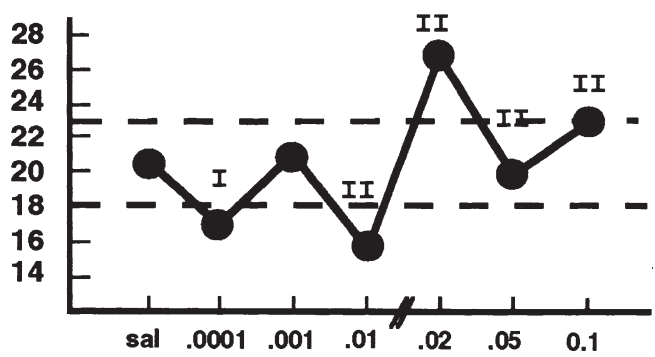

Monkey \#666 - age 9

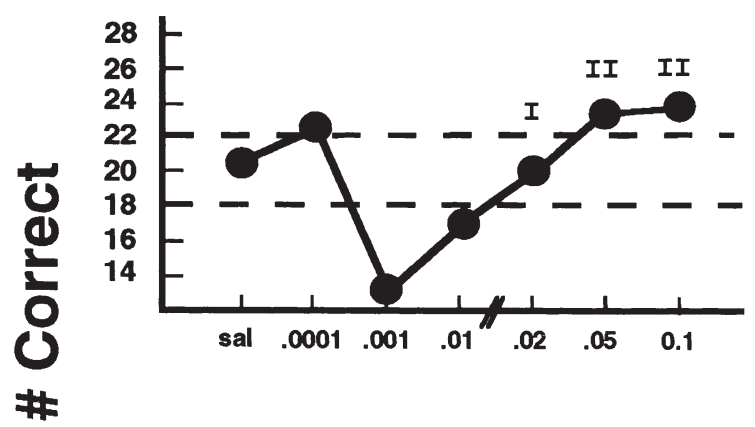

Monkey \#320 - age 15

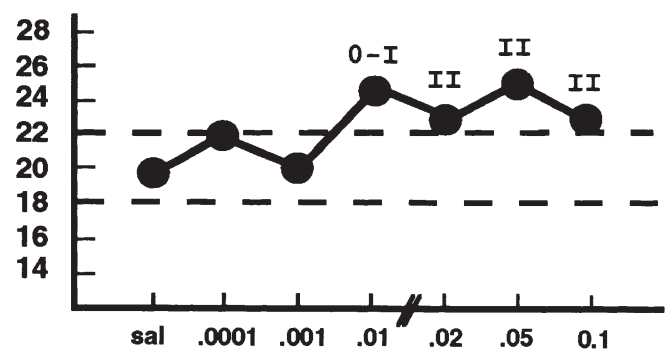

Monkey \#93-21 - age 6

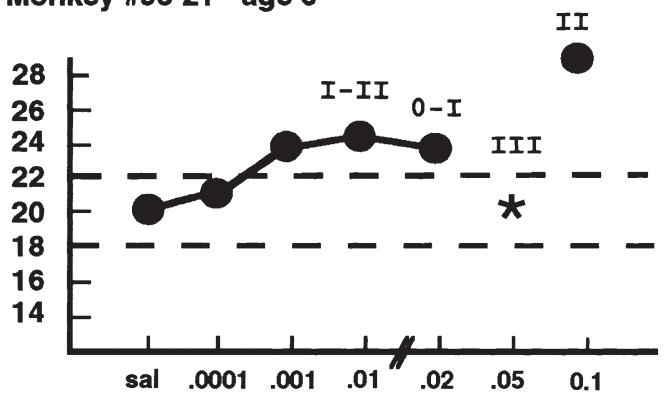

Monkey \#613 - age 11

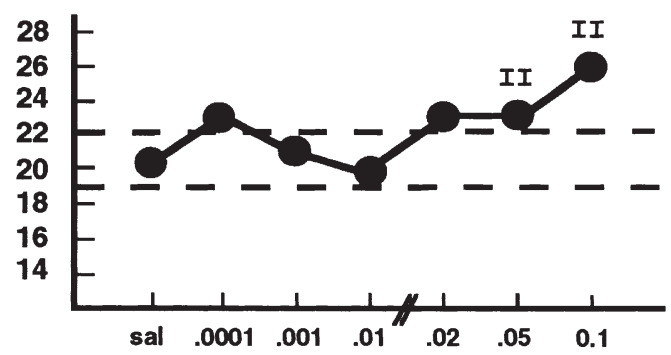

Monkey \#442 - age 15

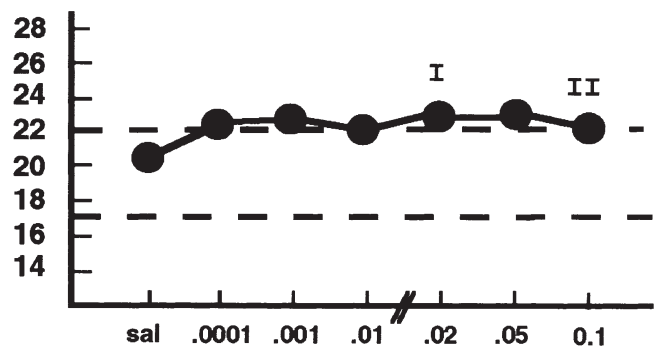

\section{Dose Clonidine $(\mathrm{mg} / \mathrm{kg}$ )}

Figure 2. The effect of clonidine on delayed response performance in individual animals. Circles represent number of trials correct out of a possible 30 trials following saline or clonidine $(0.0001-0.1 \mathrm{mg} / \mathrm{kg})$ treatment. The saline point represents the mean performance following saline administration given at a time when drug would have been given, and the testing session before drug was administered. Dashed lines represent the range of saline performance for each animal during the course of the study. Animal \#93-21 failed to complete testing following two separate administrations of $0.05 \mathrm{mg} / \mathrm{kg}$ clonidine, scoring $4 / 6$ and $9 / 10$ trials correct. The mean for all other animals at the 0.05 dose (22.8) was substituted in this empty cell in the 2-ANOVA-R. The 0 and the Roman numerals I, II, and III refer to the sedation score received by that animal during that testing session.

\section{DISCUSSION}

Higher doses $(0.02-0.1 \mathrm{mg} / \mathrm{kg})$ of the $\alpha-2$ agonist clonidine improved performance on the delayed response task in young adult monkeys, while lower doses
(0.0001-0.01 mg $/ \mathrm{kg}$ ) had no effect on task performance. The improvement in task performance was not entirely unexpected, as: 1) clonidine has previously been shown to produce a small but consistent improvement in young animals (Jackson and Buccafusco 1991); and 2) 
Table 1. Most efficacious dose of clonidine for each individual monkey

\begin{tabular}{lc}
\hline Monkey & Dose Clonidine \\
\hline $93-21$ & $0.01 \mathrm{mg} / \mathrm{kg}$ \\
$93-38$ & $0.02 \mathrm{mg} / \mathrm{kg}$ \\
320 & $0.05 \mathrm{mg} / \mathrm{kg}$ \\
442 & $0.05 \mathrm{mg} / \mathrm{kg}$ \\
666 & $0.1 \mathrm{mg} / \mathrm{kg}$ \\
613 & $0.1 \mathrm{mg} / \mathrm{kg}$ \\
\hline
\end{tabular}

guanfacine also produces improvement in young animals (Franowicz and Arnsten 1998). However, experiments in both normal human volunteers and rats have found inconsistent improvement following clonidine treatment. The doses tested in human studies ranged from $0.001-0.003 \mathrm{mg} / \mathrm{kg}$ clonidine (Coull et al. 1995a, b; Jakala et al. 1999). The present study in monkeys found beneficial effects on working memory only at doses ten times as high as those used in human studies. This suggests that the human studies have not detected the cognitive improvement seen here because the sedation at these higher doses precludes use in volunteers. The present findings also suggest that sedation may account for previous negative findings in monkeys, in which many monkeys failed to complete testing following high clonidine doses (Jackson and Buccafusco 1991). In that study, the animals were tested in their home cages using automated procedures. It is likely that the presence of the experimenter in the WGTA in the present study may compel animals to complete testing when they otherwise might be too sedated. In the current study, only one monkey was unable to complete testing following a high dose of clonidine $(0.05 \mathrm{mg} / \mathrm{kg})$.

The improvement in task performance produced by clonidine in these young animals was smaller than that found previously in aged animals (Arnsten et al. 1988). Given the age-related decline in NE, the present results are consistent with the finding that in animals experimentally depleted of catecholamines clonidine was the most beneficial in animals with the greatest NE depletion (Arnsten and Goldman-Rakic 1985).

Sedation may also be responsible for the lack of improvement in working memory in young rats following treatment with the $\alpha-2$ agonist medetomidine (Carlson et al. 1992), an agonist with potent sedative effects. Mice are, however, improved by guanfacine on a delayed alternation task (Franowicz et al. 1998) at doses comparable to those used in young adult monkeys. These data suggest that more extensive dose/response analysis in rats with less sedating agents such as guanfacine may also find improvement with higher doses.

\section{Delay analysis}

Improved task performance following clonidine in the current study was observed across all delays, including the 0 second delay. The errors occurring at 0 second delays in saline treated monkeys are likely due to the distracting effects of the experimenter rapidly raising and lowering the screen. The finding that clonidine improves performance under these conditions would support previous suggestions that clonidine is especially useful under distracting conditions (Jackson and Buccafusco 1991; Arnsten and Contant 1992). Clonidine may protect working memory from distraction by increasing delay related activity in the prefrontal cortex ( $\mathrm{Li}$ et al., accompanying paper), and/or by suppressing the processing of irrelevant stimulation to protect the contents of working memory (reviewed in Arnsten et al. 1996). In fact, distractors which disrupt performance have

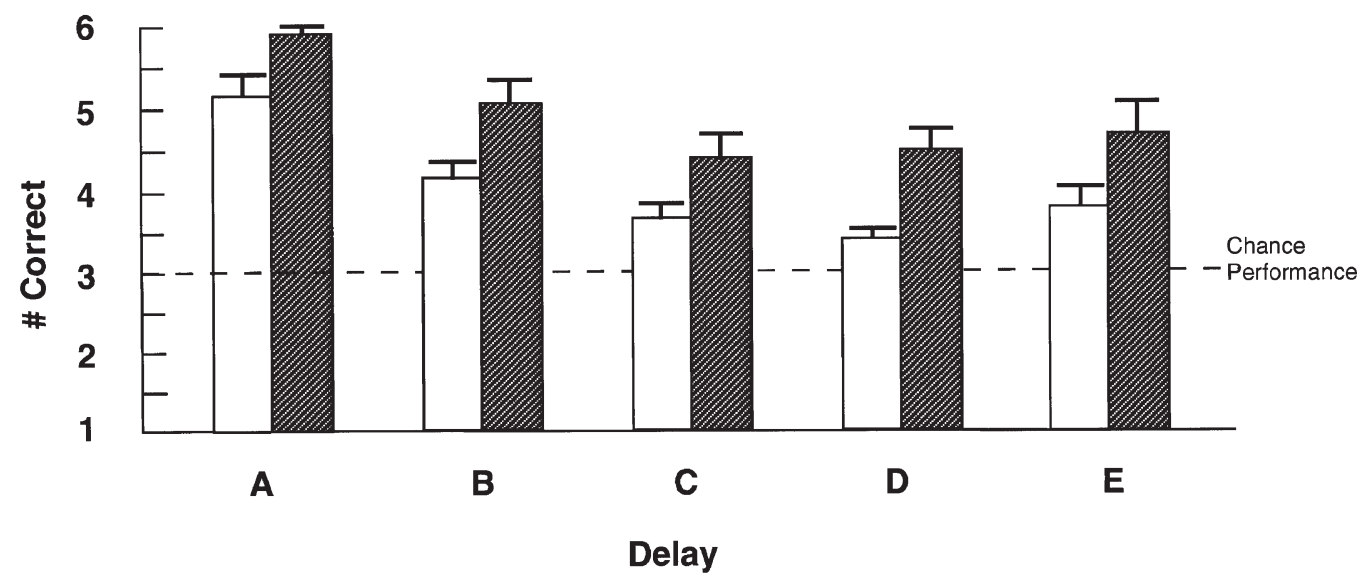

Figure 3. The mean number trials correct \pm SEM at each of the five delays following saline and each animals most efficacious dose of clondine. Open bars = saline, shaded bars = clonidine. 2-ANOVA-R revealed a significant effect of clonidine $(\mathrm{F}(6,30)=3.10, p<.02)$ and a significant effect of delay $(\mathrm{F}(4,20)=13.623, p<.0001)$ 


\section{Reversal by idazoxan}

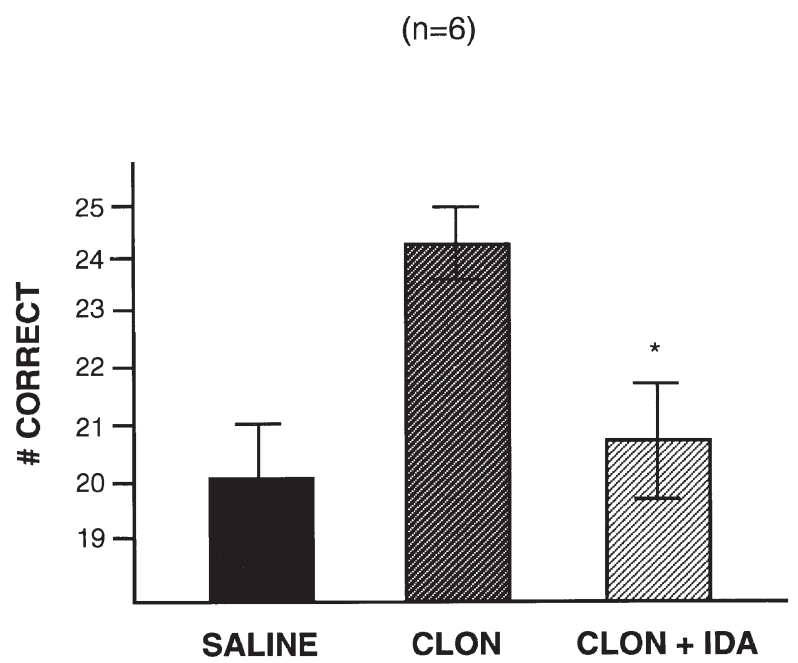

Figure 4. The effect of idazoxan on the cognitive improvement produced by each animals most efficacious dose of clonidine. Shown are mean \pm SEM number of trials correct following treatment with either saline, clonidine, or clonidine plus idazoxan $(0.1 \mathrm{mg} / \mathrm{kg})$. Idazoxan reversed the effect of clonidine on delayed response performance $(n=6)$. SAL $=$ saline, $\mathrm{CLON}=$ clonidine, IDA = idazoxan; * significant difference from clonidine.

been shown to decrease delay-related firing in PFC neurons (Fuster 1973).

Performance following the longest delays in this study likely involved prefrontal cortex interactions with hippocampal and medial temporal cortical regions, as the hippocampal complex is needed for delays greater than 10 seconds (Zola-Morgan et al. 1989). The finding that clonidine did not differentially improve performance at long delays argues against drug actions in the medial temporal lobe. This is consistent with a previous literature showing that clonidine does not improve, and may actually impair, memory functions of the medial temporal lobe (Arnsten and Goldman-Rakic 1990).

\section{Cognitive vs. Nonspecific Effects}

Sedation and Motivation. Due to the broad-ranging effects of clonidine, it has naturally been suggested that improvements on cognitive tasks may be due to nonspecific factors, such as decreased anxiety, sedation, or increased hunger. It is unlikely that the sedative effect of clonidine is indirectly responsible for improved cognitive performance for several reasons. First, clonidine does not improve non-PFC tasks (Arnsten 1998) which would be expected if non-specific performance variables were enhanced by clonidine. Also, in a previous study, a similar delayed response improvement following guanfacine treatment occurred independent of sedation (Franowicz and Arnsten 1998). Changes in motivation are also unlikely to have produced the task improvement seen here. Clonidine is known to increase food intake in rats and monkeys (Katz et al. 1989; Schlemmer et al. 1979), most likely via post-synaptic $\alpha-2$ receptors in the paraventricular nucleus of the hypothalamus (McCabe et al. 1984), possibly by a disinhibition of 'satiety' neurons. In the current study, animals were food regulated and no problems with motivation or eating all food rewards were seen at any time.

\section{Diazepam}

Adding further support to the hypothesis that clonidine's improvement is not due to non-specific factors, diazepam treatment produced no significant change in delayed response performance, even though this compound has many of the same "non-specific" actions as

\section{The effect of diazepam on delayed response performance}

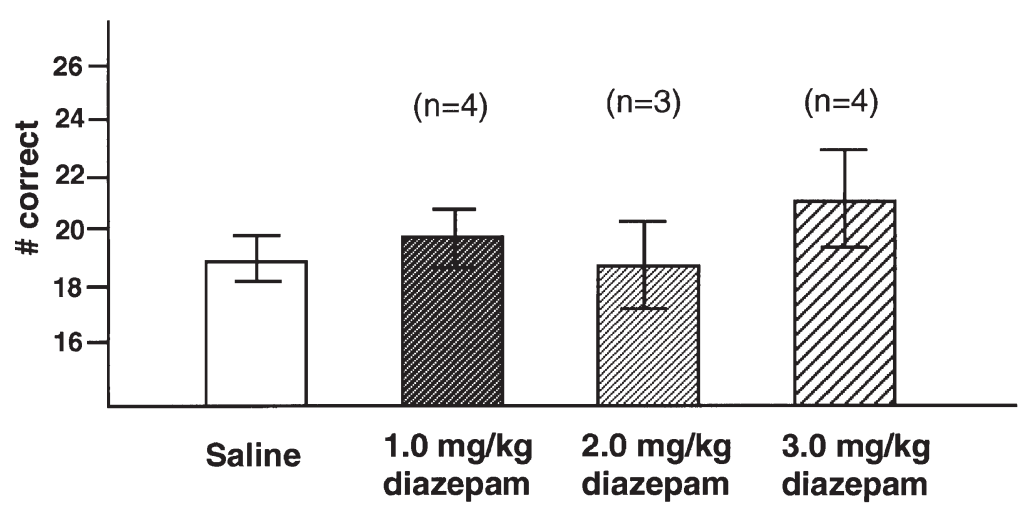

Figure 5. Mean number of trials correct \pm SEM, for saline and diazepam $(1.0,2.0$, or 3.0 $\mathrm{mg} / \mathrm{kg}$ ) treatment on delayed response performance in four animals. One animal, who was slightly ataxic, refused to complete testing following $2.0 \mathrm{mg} / \mathrm{kg}$ dizapam treatment. Thus, the bar for $2.0 \mathrm{mg} / \mathrm{kg}$ diazepam represents the remaining three animals. 
clonidine. The dose of diazepam used clinically in humans to relieve anxiety is about one tenth that used here, and diazepam in this dose range has been found to be mildly sedating (Danion et al. 1989) in humans. Non-human primates show significant deficits in response time during various tasks in the 1.0 to $2.0 \mathrm{mg} /$ $\mathrm{kg}$ dose range (Wayner et al. 1989; Hudzik and Wenger 1993), and these longer response times have been considered an indication of diazepam's sedating effects. In the current study, no significant change in sedation score was induced by diazepam treatment. This rating scale, however, is not designed to detect the subtle increases in response time which have been measured in the above mentioned primate studies. The lack of increased sedation ratings does not rule out that some slowing and anxiolytic effects occurred. Higher doses of diazepam did produce some side effects, as two animals were quieter than usual and ataxic and one animal was slightly agitated and ataxic. This agitation may be a sign of disinhibition, which is commonly seen with diazepam treatment in humans.

Previous findings suggest that diazepam at even higher doses than used here would be more likely to impair performance than improve it. Diazepam has been found to impair performance on various tests of attention, vigilance, learning and working memory (Coull et al. 1995a, b; Danion et al. 1989; Roy-Byrne et al. 1987; Kozena et al. 1995). Diazepam $(1.0 \mathrm{mg} / \mathrm{kg}) \mathrm{im}-$ paired performance and responding on a delayedmatch-to-sample task in rhesus monkeys (Hudzik and Wenger 1993). In monkeys, $3.2 \mathrm{mg} / \mathrm{kg}$ diazepam has impaired a serial probe recognition task (Castro 1995) but only $10 \mathrm{mg} / \mathrm{kg}$ diazepam impaired a delayed alternation task (Bradley and Nicholson 1984), suggesting that spatial working memory tasks such as that in the current study need higher doses for impairment to be seen. As both clonidine and diazepam have effects such as producing sedation (Wayner et al. 1989), relieving natural and drug-induced anxiety anxiety (Charney et al. 1983; Dawson et al. 1995), and reducing LC firing, the very different cognitive profiles produced by these compounds suggests that these effects do not underlie the cognitive improvement seen with clonidine treatment.

\section{Receptor Mechanisms}

Given the systemic mode of administration used in the current study and the broad distribution of $\alpha-2$ receptors in the brain, possible sites of action, both presynaptic and postsynaptic, are numerous. There is evidence, however, that at least some of the actions of clonidine beneficial to task performance are taking place at postsynaptic receptors directly in the prefrontal cortex (for review see Arnsten et al. 1996).

Presynaptic vs. Postsynaptic. Many effects of clonidine have been attributed to presynaptic $\alpha-2$ receptors, both because $\alpha-2$ receptors were the first presynaptic receptors discovered, and because the inhibitory effect of clonidine on locus coeruleus activity is pronounced (Svensson et al. 1975; Cedarbaum and Aghajanian 1977; Adams and Foote 1988). However, it is now apparent that there are plentiful post-synaptic $\alpha-2$ receptors (U'Prichard et al. 1980; Dausse et al. 1982; Dooley et al. 1983). $\alpha-2$ Receptor mRNA is enriched throughout the rat brain (Nicholas et al. 1993; Scheinin et al. 1994) and electron microscopic studies of antibodies directed to-

\section{Clonidine in reserpine-treated vs. intact monkeys}

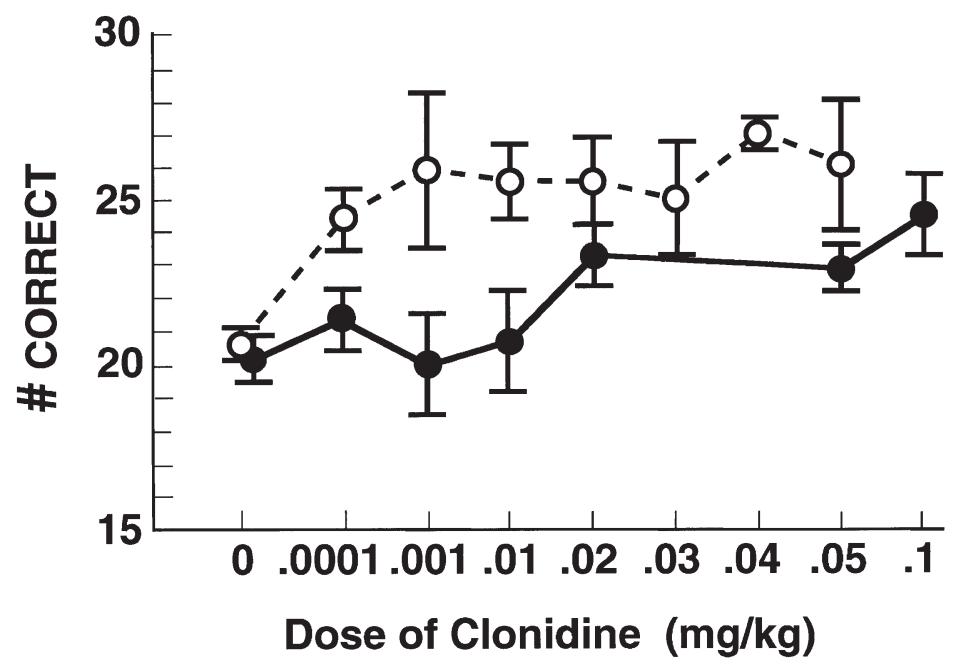

Figure 6. Shown is a comparison of the effects of clonidine in the animals in the current study and young reserpinetreated animals. Open circles represent the mean \pm SEM trials correct following clonidine treatment in reserpine treated animals (from Cai et al. 1993), and filled circles represent the mean number correct \pm SEM following clonidine treatment in the animals in the current study (from Figure 1). 
wards the $\alpha-2$ receptor in monkey have shown a majority of receptors appearing to be post-synaptic (Aoki et al. 1994). The prevalence of post-synaptic $\alpha-2$ receptors suggests that many of the effects of high doses of systemic $\alpha-2$ agonists, such as clonidine, may occur via post-synaptic receptors.

The ability of clonidine to improve task performance in animals with NE depletion supports actions at supersensitive post-synaptic receptors. A study of young, reserpine treated monkeys (Cai et al. 1993) is directly comparable to the present study, as both used the same methods and doses of clonidine. The results of the two studies are shown together in Figure 6. The same low doses which produced no effect in normal young monkeys significantly improved performance in animals depleted of NE by reserpine. Higher doses of clonidine improve task performance in both groups of animals. The finding that clonidine is more, rather than less, potent in animals in whom the presynaptic element is depleted is consistent with drug actions at post-synaptic receptors.

In addition to such post-synaptic actions in cortex, it is possible that clonidine also acted to optimize the pattern of LC firing. It has also been shown that in awake animals, clonidine's effect on LC firing is complex. Decreases in tonic baseline firing following clonidine treatment may be accompanied by preserved phasic responses to appropriate stimuli in the rat (Adams and Foote 1988) and in the monkey (Rajkowski et al. 1995). Such phasic, stimulus-related activation of the LC leads to greater NE release than tonic activation (Florin-Lechner et al. 1996). Decreases in LC baseline activity following application of other drugs have actually been shown to lead to relatively increased responsiveness to sensory stimuli (Aghajanian 1980). Thus, clonidine may have optimized the pattern of LC firing in the monkeys examined in the current study.

\section{CONCLUSIONS}

The results of the current study extend previous findings of cognitive improvement by $\alpha-2$ agonists in young animals. This improvement appears to involve postsynaptic $\alpha-2$ receptors. Previous negative results using clonidine in human studies may result from insufficient doses, necessitated by sedative side effects.

\section{REFERENCES}

Acquas E, Wilson C, Fibiger HC (1998): Pharmacology of sensory stimulation-evoked increases in frontal cortical acetylcholine release. Neuroscience 85(1):73-83

Adams LM, Foote SL (1988): Effects of locally infused pharmacological agents on spontaneous and sensory-evoked activity of locus coeruleus neurons. Brain Res Bull 21:395-400

Aghajanian GK (1980): Mescaline and LSD facilitate the activation of locus coeruleus neurons by peripheral stimuli. Br Res 186:492-498

Aoki C, Go C-G, Venkatesan C, Kurose H (1994): Perikaryal and synaptic localization of $\alpha$-2a-adrenergic receptorlike immunoreactivity. Br Res 650:181-204

Arnsten AFT, Goldman-Rakic PS (1985): $\alpha-2$ adrenergic mechanisms in prefrontal cortex associated with cognitive decline in aged human primates. Science 230:12731276

Arnsten AFT, Cai JX, Goldman-Rakic PS (1988): The $\alpha-2$ adrenergic agonist guanfacine improves memory in aged monkeys without sedative or hypotensive side effects: Evidence for $\alpha-2$ receptor subtypes. J Neurosci 8(11): 4287-4298

Arnsten AFT, Goldman-Rakic PS (1990): Analysis of $\alpha-2$ adrenergic agonist effects on the delayed non match-tosample performance of aged rhesus monkeys. Neurobiol Aging 11:583-590

Arnsten AFT, Contant TA (1992): $\alpha-2$ adrenergic agonists decrease distractibility in aged monkeys performing the delayed response task. Psychopharmacology 108:159169

Arnsten AFT, Steere JC, Hunt RD (1996): The contribution of $\alpha-2$ noradrenergic mechanisms to prefrontal cognitive function. Arch Gen Psychiatry 53(5):448-455

Arnsten AFT (1998): Catecholamine modulation of prefrontal cortical cognitive function. TICS 2(11):436-447

Bakchine S, Lacomblez L, Benoit N, Parisot D, Chain F, Lhermitte F (1989): Manic-like state after bilateral orbitofrontal and right temporoparietal injury: Efficacy of clonidine. Neurology 39:777-781

Bradley CM, Nicholson AN (1984): Activity of the chloroand triazolo-bensodiazepines. Behavioural studies in the monkey (Macaca mulatta). Neuropharmacology 23(3):327-331

Brozoski T, Brown RM, Rosvold HE, Goldman PS (1979): Cognitive deficit caused by regional depletion of dopamine in the prefrontal cortex of the rhesus monkey. Science 205:929-932

Cai J-X, Ma Y, Xu L, Hu X (1993): Reserpine impairs spatial working memory performance in monkeys: Reversal by the $\alpha$-2-adrenergic agonist clonidine. Br Res 614:191-196

Carlson S, Tanila H, Rama P, Mecke E, Pertovaara A (1992): Effects of medetomidine, an $\alpha-2$ agonist, and apitamezole, an $\alpha-2$ antagonist, in spatial memory performance in adult and aged rats. Behav Neural Biol 58:113-119

Castro CA (1995): Primacy and recency effects in rhesus monkeys (macaca mulatta) using a serial probe recognition task. I. Effects of diazepam. Psychopharmacology 119:421-427

Cedarbaum JM, Aghajanian GK (1977): Catecholamine receptors on locus coeruleus neurons: Pharmacological characterization. Eur J Pharmacol 44(4):375-385

Charney DS, Heninger GR, Redmond DE (1983): Yohimbine induced anxiety and increase noradrenergic function in humans: Effects of diazepam and clonidine. Life Sci 33:19-29 
Clark CR, Geffen GM, Geffen LB (1989): Catecholamines and the covert orienting of attention in humans. Neuropsychology 27(2):131-139

Cohen DJ, Detlor J, Young JG, Shaywitz BA (1980): Clonidine ameliorates gilles de la tourette syndrome. Arch Gen Psychiatry 37:1350-1357

Coull JT, Frith CD, Dolan RJ, Frackowiak RSJ, Grasby PM (1997): The neural correlates of noradrenergic modulation of human attention, arousal and learning. Eur J Neurosci 9:589-598

Coull JT, Middleton HC, Robbins TW, Sahakian BJ (1995a): Contrasting effects of clonidine and diazepam on tests of working memory and planning. Psychopharmacology 120:311-321

Coull JT, Middleton HC, Robbins TW, Sahakian BJ (1995b): Clonidine and diazepam have differential effects on tests of attention and learning. Psychopharmacology 120:322-332

Danion J-M, Zimmerman M-A, Willard-Schroeder D, Grange D, Singer L (1989): Diazepam induces a dissociation between explicit and implicit memory. Psychopharmacology 99:238-243

Dausse J-P, Quan-Bui KHL, Meyer P (1982): $\alpha-1$ and $\alpha-2-$ adrenoceptors in rat cerebral cortex: Effects of neonatal treatment with 6-OHDA. Eur J Pharmacol 78:15-20

Dawson GR, Rupniak NM, Iversen SD, Curnow R, Tye S, Stanhope KJ, Tricklebank MD (1995): Lack of effect of CCKB receptor antagonists in ethological and conditioned animal screens for anziolytic drugs. Psychopharmacology 121(1):109-117

Dooley DJ, Bittiger H, Hauser KL, Bischoff SF, Waldmeier PC (1983): Alteration of central $\alpha-2$ and $\beta$ - adrenergic receptors in the rat after DSP-4, a selective noradrenergic neurotoxin. Neuroscience 9(4):889-898

Fields RB, Van Kammen DP, Peters JL, Rosen J, Van Kammen WB, Nugent A, Stipetic S, Linoila M (1988): Clonidine improves memory function in schizophrenia independently form change in psychosis. Schiz Res 1:417-423

Florin-Lechner SM, Druhan JP, Aston-Jones G, Valentino RJ (1996): Enhanced norepinephrine release in prefrontal cortex with burst stimulation of the locus coeruleus. $\mathrm{Br}$ Res 742:89-97

Franowicz JS, Arnsten AFT (1998): The $\alpha$-2A noradrenergic agonist, guanfacine, improves delayed response performance in young adult rhesus monkeys. Psychopharmacology 136:8-14

Franowicz JS, Kessler L, Morgan C, Arnsten AFT (1998): The $\alpha-2$ noradrenergic agonist guanfacine improves spatial working memory in wild type mice but not mice with point mutations of the gene for the $\alpha-2 \mathrm{~A}$ receptor. Soc Neurosci Abstr 24:711

Frith CD, Dowdy J, Ferrier IN, Crow TJ (1985): Selective impairment of paired associate learning after administration a centrally acting adrenergic agonist (clonidine). Psychopharmacology 87:490-493

Fuster JM (1973): Unit activity in prefrontal cortex during delayed-response performance: Neuronal correlates of transient memory. J Neurophys 36(1):61-78

Grant SJ, Huang YH, Redmond DE (1980): Benzodiazepines attenuate single unit activity in the locus coeruleus. Life Sci 27:2231-2236

Hardy M-C, Lecrubier Y, Widlocher D (1986): Efficacy of clonidine in 24 patients with acute mania. Am J Psychiatry 143(11):1450-1453

Hoehn-Saric R, Merchant AF, Keyser ML, Smith VK (1981): Effects of clonidine on anxiety disorders. Arch Gen Psychiatry 38:1278-1282

Hudzik TJ, Wenger GR (1993): Effects of drugs of abuse and cholinergic agents on delayed matching-to-sample responding in the squirrel monkey. JPET 265:120-127

Hunt RD, Mindera RB, Cohen DJ (1985) Clonidine benefits children with ADD and hyperactivity: report of a double-blind placebo-crossover therapeutic trial. J Am Acad Child Psychiatry 24(5):617-629

Jackson WJ, Buccafusco JJ (1991): Clonidine enhances delayed matching-to-sample performance by young and aged monkeys. Pharmacol Bio Behav 39:79-84

Jakala P, Riekkinen M, Sirvio J, Koivisto E, Kejonen K, Vanhanen M, Riekkinen PJ (1999): Guanfacine, but not clonidine, improves planning and working memory performance in humans. Neuropsychopharmacology 20 (5):460-470

Katz NL, Sobaski N, Sanchez J, Young JE, Schlemmer RF (1989): Differential effects of clonidine analogs on food intake in rabbits and monkeys. Pharmacol Biochem Behav 34:433-437

Kozena L, Frantik E, Horvath M (1995): Vigilance impairment after a single dose of benzodiazepines. Psychopharmacology 119:34-46

Mair RG, McEntee WJ (1986): Cognitive enhancement in Korsakoff's psychosis by clonidine: A comparison with 1-dopa and ephedrine. Psychopharmacology 88:374-380

McCabe JT, DeBellis M, Leibowitz SF (1984): Clonidineinduced feeding: analysis of central sites of action and fiber projections mediating this response. Br Res 309:85104

Murai T, Yoshida Y, Koide S, Takada K, Misaki T, Koshikawa N, Cools A (1998): Clonidine reduces dopamine and increases GABA in the nucleus accumbens: An in vivo microdialysis study. Pharmacol Biochem Behav 60(3): 695-701

Nicholas AP, Pieribone V, Hökfelt T (1993): Distributions of mRNAs for a-2 adrenergic receptor subtypes in rat brain: An in situ hybridization study. J Comp Neurol 328:575-594

Rajkowski J, Ivanova S, Kubiak P, Aston-Jones G (1995): Improved vigilance performance in monkey associated with altered locus coeruleus (LC) activity after clonidine. Soc Neurosci Abstr 21:2092

Rama P, Linnankoski I, Tanila H, Pertovaara A, Carlson S (1996): Medetomidine, atipamezole, and guanfacine in delayed response performance of aged monkeys. Pharmacol Biochem Behav 55(3):415-422

Rossetti ZL, Portas C, Pani L, Carboni S, Gessa GL (1990): Stress increases noradrenaline release in the rat frontal cortex: Prevention by diazepam. Eur J Pharm 176:229-231

Roy-Byrne PP, Uhde TW, Holcombe H, Thompson K, King 
AK, Weingartner H (1987): Effects of diazepam on cognitive processes in normal subjects. Psychopharmacology 91:30-33

Scheinin M, Lomasney JW, Hayden-Hixson DM, Schambra UB, Caron MG, Lefkowitz RJ, Fremeau RT (1994): Distrib. of $\alpha-2$ adrenergic recept. subtype gene express. in rat brain. Mol Brain Res 21:133-149

Schlemmer RE, Casper RC, Narasimhacheri N, Davis JM (1979): Clonidine induced hyperphagia and weight gain in monkeys. Psychopharmacology 61:233-234

Schneider JS, Kovelowski CJ (1990): Chronic exposure to low doses of MPTP, I: Cognitive deficits in motor asymptomatic monkeys. Br Res 519:122-128

Schulze GE, Slikker W, Paule MG (1989): Multiple behavioral effects of diazepam in rhesus monkeys. Pharmacol Biochem Behav 34(1):29-35

Svensson TH, Bunney BS, Aghajanian GK (1975): Inhibition of both noradrenergic and serotonergic neurons in brain by the a-adrenergic agonist clonidine. Br Res 92:291

Tanila H, Rama P, Carlson S (1996): The effects of prefrontal intracortical microinjections of an $\alpha-2$ agonist, $\alpha-2$ antagonist and lidocaine on the delayed alternation performance of aged rats. Brain Res Bull 40(2):117-119

U'Prichard DC, Reisine TD, Mason ST, Fibiger HC, Yamamura HI (1980): Modulation of rat brain $\alpha-1$ and $\beta$-adrenergic receptor populations by lesion of the dorsal noradrenergic bundle. Br Res 187:143-54

Wayner J, Dalterio SL, Geller I, Hartmann RJ (1989): Ethanoldiazepam interactions on delayed-match-to- sample performance in baboons. Brain Res Bull 23(4-5):333-338

Zola-Morgan S, Squire LR, Amaral DG (1989): Lesions of the hippocampal formation but not lesions of the fornix or the mammillary nuclei produce long-lasting memory impairment in monkeys. J Neurosci 9(3):898-913 